\title{
Genotoxicity of engineered nanoparticles in higher plants
}

Manosij Ghosh $^{1,2, \text { a, } \neq}$, Ilika Ghosh ${ }^{1, \neq}$, Lode Godderis $^{2,3}$, Peter Hoet $^{2}$, Anita Mukherjee $^{1, \#}$

${ }^{1}$ Cell Biology and Genetic Toxicology Laboratory, CAS Department of Botany, University of Calcutta; 35 Ballygunge circular road, Kolkata-700019, India

${ }^{2}$ KU Leuven, Department of Public Health and Primary Care, Unit of Environment and Health, 3000 Leuven, Belgium

${ }^{3}$ IDEWE, external service for prevention and protection at work, 3001 Heverlee, Belgium

*gmanosij@gmail.com; \# anitamukherjee28@gmail.com

$\neq$ Co-first authors; the authors have equal contribution

\section{Contents}

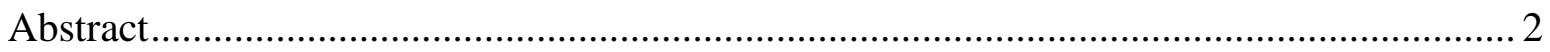

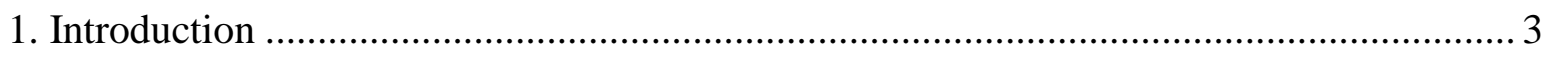

2. Plants as model systems for genotoxicity assessment of nanoparticles .......................... 3

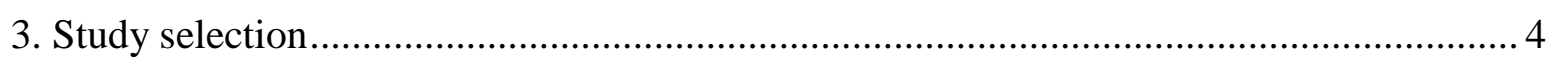

4. Physicochemical characterization and interaction with exposure media .........................5

5. Uptake and bio distribution- Crossing biological barriers............................................ 7

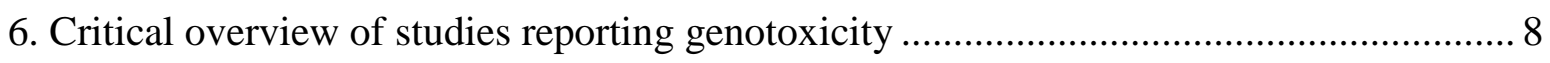

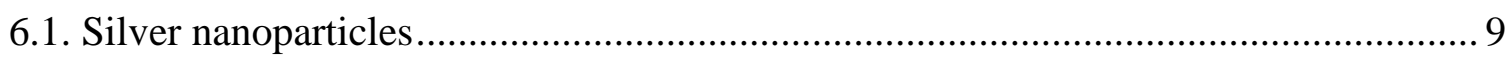

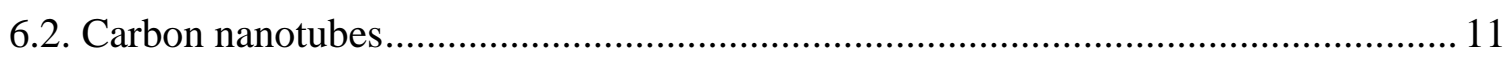

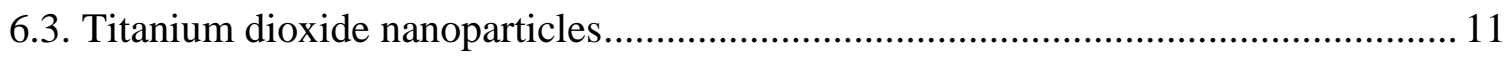

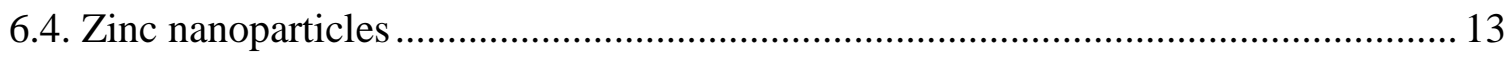

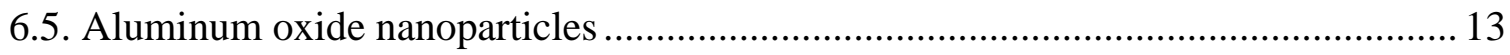

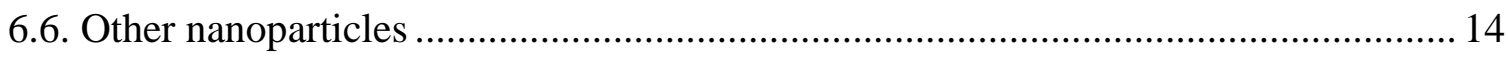

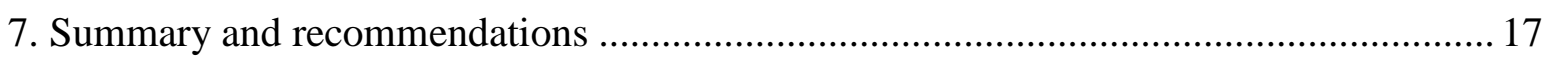




\begin{abstract}
Nanoparticles (NPs) are an emerging environmental threat. However, studies of NPs in different environmental components are limited. In this review, we discuss studies that have evaluated the genotoxicity of NPs in higher plants. Among the 29 studies reviewed, silver NPs were most studied ( $n=7$ articles), with fewer studies reporting the genotoxicity of carbon nanotubes $(n=3)$, titanium dioxide NPs $(n=4)$, and zinc oxide NPs $(n=3)$. Most of the genotoxicity studies were performed in the model plant systems Allium sp ( $n=22)$, Nicotiana $\mathrm{sp}$ $(n=4)$ and Vicia sp $(n=4)$ using chromosome aberration $(n=22)$, micronucleus $(n=15)$ and comet assays (n=14). Genotoxicity was observed in most of the studies; however, many studies did consider key determinants of NP toxicity such as particle characterization, dissolution, and uptake. From this review, we propose a set of guidelines that should be considered when reporting results of NP toxicity in plants.
\end{abstract}

Keywords: Nanotoxicology; plant bioassay; genotoxicity; Comet assay; micronucleus; chromosome aberration 


\section{Introduction}

Novel properties of materials at the nano-scale have led to a wide range of applications in consumer products and the healthcare industry. As a consequence, the production and use of nanoparticles (NPs) has increased exponentially, which has led to higher probability of NP release into the environment. Keller et al.[1] estimated that $60 \%$ to $89 \%$ of nanomaterials produced ( $>100$ tons/year) are expected to end up in landfills, with the highest amount expected in Asia, followed by Europe and America. The release could be direct (NP production, wastewater treatment, use of NP containing agrochemicals, waste disposal during production) or indirect (use of consumer products and disposal, recycling units etc.) [2] (Fig. 1). A more recent study [3] based on material flow analysis further described the effect of waste management and environmental release in Europe. The US Environmental Protection Agency $[4,5]$ has listed some of the most widely used NPs, including several metal/metal oxide NPs and carbon-based NPs, as emerging environmental threats, capable of affecting diverse biological systems.

\section{< Figure 1>}

\section{Plants as model systems for genotoxicity assessment of NPs}

Plants are considered excellent genetic models for screening and monitoring environmental mutagens [6-8]. Being eukaryotes, higher plants have similar chromosomal morphology, mechanism of mutation and cell division process as animals [9]. However, they rank higher than animal systems because of their sensitivity to detect single or complex mixtures of mutagens and toxic compounds even at low concentrations. The key advantage of using plant bioassays is the versatility of genetic endpoints from DNA strand breaks to point mutations [10]. Such bioassays are inexpensive, quick, and easy to use, and can be used with a range of environmental conditions, $\mathrm{pH}$ and temperature. Moreover, they do not require any ethical regulations as for animal models and cell lines.

Higher plant species such as Allium cepa, Vicia faba, Nicotiana tabacum, Zea mays, Tradescantia and Hordeum vulgare are widely used for assessing environmental mutagens. A. cepa and $V$. faba are accepted by regulatory bodies as models for testing genotoxicity [11,12]. Because of its efficacy, the root tip chromosome aberration (CA) assay with A. cepa and V. faba has been validated by The International Programme on Chemical Safety (World Health Organization), United Nations Environmental Programme and International Labor 
Organization as the standard test for screening chemicals and in situ monitoring of genotoxicity [12-16].

The environmental discharge of nanomaterials causes their accumulation at various trophic levels. Plants, as primary producers, constitute a vital link [17]. As sessile organisms, they are highly susceptible to nanotoxicity and can take up NPs by all routes of exposure soil, water and air. Hence, plant models are highly recommended as a first-tier bioassay system for detecting the possible genotoxicity of various nanomaterials. In recent years, model plants such as Arabidopsis and Nicotiana have increasingly been used for toxicity studies of metal NPs because of their standardized culture methods and completely sequenced genomes $[18,19]$. The ease of germination, growth, maintenance, handling and treatment allow the use of Allium and Vicia as efficient test systems for nanotoxicity evaluations [20-24]. A. cepa root tip bioassay is most suitable for identifying genotoxic concentrations of NPs, whereas $V$. faba has emerged as a standard model for studying genotoxicity from both root and shoot. These findings can further be correlated with NP uptake and biodistribution within the plant body. A few studies have also examined edible plants such as maize, tomato, eggplant and radish.

Therefore, plant bioassays can be used for efficient classification of different NPs as clastogens and/or mutagens. Results can provide further clues on the potential genotoxicity and carcinogenicity of NPs in animal systems, which can in turn contribute to their environmental safety appraisal. However, reports of the genotoxicity of nanomaterials in plant systems are scarce and such studies require further optimization with strategic approaches. Here we review the available literature and provide recommendations to support the establishment of plants as model systems for study of NP-induced genotoxicity.

\section{Study selection}

PubMed was searched on January 31, 2018 for publications related to NP toxicity. More than 17,355 publications addressed the issue of "NP toxicity", the release and impact of NPs. The adverse effects in humans are of primary concern, as reflected by the large number of studies in vitro and in vivo, whereas studies in ecosystems are limited. In an ecotoxicological context, plant systems can provide relevant information for a picture of the toxicological footprint of several compounds. Additionally, as discussed earlier, plant-based toxicity assays have widely been used as alternative models, with comparable outcomes to those obtained in animal studies [25]. However, relatively few studies $(n=988 ;$ PubMed search string "Nanoparticle toxicity" and "Plants") have addressed toxicity in plants. These studies could be 
classified by the reported effects on germination ( $\mathrm{n}=98$, "Nanoparticle toxicity" AND "Plants" AND "Germination"), cytotoxicity ( $\mathrm{n}=121$, "Nanoparticle toxicity" AND "Plants" AND "Cytotoxicity"), and DNA damage ( $\mathrm{n}=$ 50, "Nanoparticle toxicity" AND "Plants" AND "DNA damage"), and often explained by oxidative stress $(n=159$, "Nanoparticle toxicity" AND "Plants" AND "Oxidative stress") as the mechanism behind such toxicity. In this review, we

critically discuss studies examining genotoxicity of NPs in model plant systems by using one or more of the standard genotoxicity testing methods, including comet, micronucleus (MN) and CA assay.

\section{Physicochemical characterization of NPs and interaction with exposure media}

Physicochemical properties of NPs greatly affect plant nanotoxicity studies. Size, shape, crystal-phase, surface area, porosity, aggregation/agglomeration state and surface charge in addition to chemical composition and purity are important determinants of NP interaction, uptake and toxicity. The influence of NPs on toxicity in terms of their size, surface area and other physicochemical properties are well established from in vitro and in vivo studies [26-30]. Also, the dispersion/exposure media greatly affects NP toxicity [31-34]. Therefore, extensive characterization of NPs in the primary state and exposure conditions are equally important for proper risk assessment in nanotoxicological plant studies. Most studies reporting the toxicity of NPs in plants have characterized primary particles, but characterization of experimental conditions are mostly absent or inadequate. Properties such as such as $\mathrm{pH}$, size distribution, dissolution and interaction with components of exposure media are often missing. Also, most of these studies use static-hydroponic exposure conditions, conventionally used for soluble chemicals. Under such circumstances, the hydrodynamic characteristics change during the treatment.

A key alteration in NPs is the occurrence of agglomerates (formation of loose clumps) or aggregates (tight clumps of bulk particles) evaluated by an increase in mean hydrodynamic diameter/size. This feature is directly related to colloidal stability. NP suspensions are chiefly colloidal because they comprise homogenous, mostly insoluble mixtures of evenly dispersed particles in solvent. An estimation of charge (zeta potential) provides crucial information on stability in the colloidal state. NP suspensions with zeta potentials of $>+30$ or $<-30 \mathrm{mV}$ are highly stable. When charge is diminished, with zeta potential $<|20 \mathrm{mv}|$, agglomeration is prominent [35]. In relation to charge, the polydispersity index (PDI) of the suspensions is a direct measure of agglomeration/aggregation. PDI values close to 1 indicate polydispersity and hence colloidal destabilization. Monodisperse suspensions ideally show PDI values close to 
0.1. Monitoring the above features before and after the exposure period and at all treatment concentrations is highly recommended for genotoxicity analyses and dose-response studies. Only a few reports have explored these aspects in terms of toxicity. Ghosh et al. [36] showed time- and concentration-dependent colloidal destabilization (low zeta potential and PDI close to 1) of nano zerovalent iron (nZVI) after $24 \mathrm{~h}$ of hydroponic exposure to A. cepa bulbs, leading to genotoxicity. Similar findings were reported by Bhuvaneshwari et al. [37] in green algae treated with nZVI. The authors reported a time- and concentration-dependent increase in hydrodynamic size, which was related to cytotoxicity. Adding to the complexity is that although the hydroponic exposure condition accompanied by detailed characterization (size distribution, surface charge, dissolution etc.) provides better understanding, it does not account for the complex nature of soil and interaction thereof. Nor do the studies account for an increase in aggregation over time and subsequent sedimentation of particles in aqueous suspension altering the effective exposure concentration. In addition, we lack information on the potential transformation/dissolution of the nanomaterial in the exposure condition. The importance of transformation/dissolution and its association with NP toxicity has been reported for particles such as silver NPs (Ag-NPs [38,39]), zinc oxide NPs (ZnO-NPs [40,41]) and cerium oxide NPs $\left(\mathrm{CeO}_{2}\right.$-NPs [40]). Factors such as NP morphology, dissolution kinetics, morphology, and interaction with complex macromolecules can affect their toxicity profiles, so lack of such information may often lead to over-/underestimating the toxicity of the NP examined.

Only a limited number of studies have reported on NP behavior in soil $[42,43]$. Darlington et al.[44] reported the changes in properties of aluminum oxide NPs $\left(\mathrm{Al}_{2} \mathrm{O}_{3}-\mathrm{NPs}\right)$, finding that transport of particles through a soil column was affected by solution type, surface properties, size and agglomeration state and surface charge. Tourinho et al.[45] and Cornelis et al.[46] reviewed the fate and effect of NPs in soil, indicating the significant role of physicochemical properties in NP-soil interactions and the impact. However, because of the complex nature of the NP-soil interaction, soil as an exposure medium has not routinely been used in toxicological studies. Additionally, some studies have used solid/semi-solid culture media for exposure [47-49]; however, the mobility of particles and their interaction with components of culture media has not been reported. Lee et al.[50] reported the lower toxicity of Ag-NPs in soil as compared to agar media. This reduction was explained by the reduced bioavailability of NPs in soil (because of binding to organic substances, greater aggregation in pore water and sorption to soil particles) as compared with agar. However, such studies are few. 
Moreover, the experimental physicochemical characteristics of NPs can be altered in an environmental setting with natural exposure conditions, for difficulties in in situ data prediction.

\section{Uptake and bio distribution of NPs: crossing biological barriers}

The physicochemical properties of NPs determine NP interaction, uptake, and subsequent distribution within the plant system. Studying and understanding NP uptake is critical for properly interpreting toxicological data. However, because of the complex nature of plant anatomy and inter-/intra-species diversity in cellular architecture, such analysis and interpretation is difficult. Some toxicological studies are supported by information on uptake (qualitative/semi-quantitative), but studies on the bio-distribution and cellular uptake of NP in plants and the mechanism is not well understood.

\section{<Figure 2>}

The effect of plant anatomy on uptake and distribution of NPs was elegantly reviewed by Schwab et al.[51]. The possible mode of uptake and distribution is schematically presented in Figure 2. The Schwab et al. review highlighted the role and inter-/intra-species variability in chemical composition/thickness/architecture of the cell and cell wall and the environmental conditions, which can influence them. It also highlighted the role of symbiotic bacteria and mycorrhizae in protecting and/or increasing NP uptake. The role of the plant vasculature was discussed: vascular translocation can be proportional to water flux, which in turn is strongly related to the drought tolerance and physiology of the plant. Xylem translocation of NPs is well documented [51,52], but few studies have reported phloem translocation [53,54]. A recent study of watermelon (Citrullus lanatus) [54] used inductively coupled plasma-mass spectroscopy (ICP-MS) to study the translocation of gold NPs from leaf to root. The authors suggested that NPs could enter directly by penetration or by stomatal opening and provided evidence of phloem transport. They also observed that uptake, distribution and accumulation depended on physicochemical properties. Ma et al.[53] demonstrated the "root-to-shoot-to-root" translocation of $\mathrm{CeO}_{2}-\mathrm{NPs}$, indicating the role of both xylem and phloem transport in the distribution of NPs in the plant. Adding to the complexity of the chemical composition of exposure media in the exposure media-NP interaction, NPs can affect nutrient uptake by plants and thus could alter/affect the observed response of NP uptake on toxicological outcome. This is a critical aspect but has only been studied by a few researchers [55].The study by Zaytseva et al. [55] demonstrated the role of micronutrient distribution as a critical determinant in multiwalled CNT (MWCNT) phytotoxicity and oxidative stress. However, here we focus on the 
localization of NPs in the target tissue/cellular compartment with use of scanning electron microscopy-energy-dispersive X-ray (SEM-EDX), transmission electron microscopy (TEM) and/or ICP-MS. Cellular uptake of NPs in plants was reviewed by Ma et al.[56]. SEM-EDX was used in some of studies to qualitatively demonstrate the amount of NP adsorption and uptake[21,36,57,58]. Cellular uptake of NPs was most often studied by TEM [21,57,59-61]. Other studies have relied on atomic absorption and ICP-MS to study the internalization of particles[36,61].

\section{Critical overview of studies reporting genotoxicity}

In focusing on genotoxicity in plants, we examined studies reporting DNA damage by their use of comet assay ( $\mathrm{n}=20$, "Nanoparticle toxicity" AND "Plants" AND "Comet assay"), CA ( $\mathrm{n}=$ 24, "Nanoparticle toxicity" AND "Plants" AND "Chromosome aberration") and MN assay (n= 12, "Nanoparticle toxicity" AND "Plants" AND "micronucleus assay"). Additional literature searches were performed in Scopus and Google Scholar databases. A total of 29 studies was retained based on their use of comet assay, $\mathrm{CA}$ and $\mathrm{MN}$ alone or in combination. Here we highlight the particle characterization, treatment procedure and outcome of these studies. To efficiently understand and compare these studies, relative frequency $(R F)$ was calculated for each of the studies.

- $\mathrm{RF}$ comet assay $($ RFcom $)=\%$ tail DNA in treatment/\%tail DNA in control

- $\mathrm{RFCA}(R F c a)=\% \mathrm{CA}$ in treatment $/ \% \mathrm{CA}$ in control

- $\mathrm{RF} \mathrm{MN}(R F m n)=\mathrm{MN}$ in treatment/MN in control

In case of a bell-shaped dose response, treatment refers to the condition with the highest effect; in studies showing a linear response, it is the highest concentration tested.

Of note, the $R F$ values we calculated are only indicative and are often not comparable because of differences in particle types, concentrations, test systems and experimental methods. The RF values calculated for each of the study endpoints are presented in Table 1 and can only be used for comparison when the studies were performed with the exact same NP in a specific test system. These values may also be used for future studies as a reference range.

Additionally, each of the studies was assigned a quality score (Supplementary Table 1) out of a maximum possible score of 10 . The scoring criteria is not based on any established method but was developed for this study, taking into account important determinants such as particle properties (primary and dispersion), uptake/distribution, and genotoxicity study 
method. The quality of the reviewed studies is summarized in Table 1. In the following section, we discuss the results of genotoxicity assays based on NP type. The studies reported for each of the NPs somewhat reflect the global production/use of these NPs (titanium dioxide [TiO2] > $\mathrm{ZnO}>\mathrm{CNTs}>\mathrm{Ag} \geq \mathrm{AlO}$ )[62]. The NPs most-studied by plant genotoxicity assays are Ag-NPs $(\mathrm{n}=7)$; fewer studies are available for CNTs $\left.(\mathrm{n}=3), \mathrm{TiO}_{2}-\mathrm{NPs}(\mathrm{n}=4), \mathrm{ZnO}-\mathrm{NPs} ; \mathrm{n}=3\right)$, and $\mathrm{Al}_{2} \mathrm{O}_{3}$ NPs; $n=2$ ). All other NPs including gold (Au-NP; n=2) are discussed under "Other NPs".

\subsection{Silver NPS}

In one of the earliest studies, Kumari et al. [63] reported the toxicity of Ag-NPs by using A. cepa CA assays. The study was supported by characterization of Ag-NPs $(<100 \mathrm{~nm})$ provided by the manufacturer (Sigma Aldrich, USA). Interpretation of the results of the study is limited by the lack of proper characterization of the particle in the exposure condition, as is the case for most of the earlier studies. The authors observed a decrease in mitotic index (MI), induced by most of the concentrations tested. An increase in CA was observed in the tested concentrations $(0-100 \mu \mathrm{g} / \mathrm{ml})$. However, the results of CA were represented only qualitatively (presence/absence) and hence only allow for a limited comparison with other studies. Later, our group [22] investigated the same Ag-NPs ( $\leq 100 \mathrm{~nm}$; Sigma Aldrich, USA) for genotoxicity in A. cepa and $N$. tabacum. The study was supported by characterization of primary particles (SEM, TEM, XRD), in addition to what was provided by the manufacturer. However, particle characterization in the exposure condition was limited. The measurements were performed only for the stock concentration, with dynamic light scattering (DLS) suggesting particle aggregation and zeta potential $-4.86 \mathrm{mV}$. The results of comet assay revealed significant genotoxicity in root and leaf cells of A. cepa $(R F$ com $=7.5)$ and N. tabacum $(R F c o m=2.5)$ with doses of 25 to $75 \mu \mathrm{g} / \mathrm{ml}$. The genotoxic response was supported by uptake in A. cepa root cells on TEM. These studies provide an estimation of genotoxicity of the particles but do not consider the effect of Ag ion. In a later publication by Prokhorova et al.[64], the authors studied the genotoxic effect of colloidal Ag-NPs in A. cepa by using CA and MN assays. The primary size $(5-50 \mathrm{~nm})$ was determined by TEM; however, particle sizes in the treatment condition were not reported. The authors indicated that the dispersion for treatment was prepared in distilled water, but the duration of treatment was not reported. The study reported an increase in MI (at $50 \mu \mathrm{g} / \mathrm{mL}$ ) but no changes in \%CA $(R F c a=1)$ or \% MN $(R F m n=0.83)$. The authors concluded that the studied particles were "genetically safe". Patlolla et al.[20] reported the genotoxicity of Ag-NPs (60 $\mathrm{nm} ; 400 \mathrm{~m}^{2} / \mathrm{g}$ surface area) by using CA and MN assays with $V$. faba. Similar to most studies of $A$. cepa, an increase in CA $(R F c a=9.45)$ and $\mathrm{MN}(R F m n=3.14)$ was observed in $V$. faba. 
Again, the absence of characterization and uptake partially limits the interpretation of the results.

Not many studies have reported the genotoxicity of surface functionalization of AgNPs. Cvjetko et al.[65] described the toxicity of surface-functionalized Ag-NPs in A. cepa by using a battery toxicity test. The authors reported higher genotoxicity of cetyltrimethylammonium bromide (CTAB)-coated Ag-NPs ( $\sim 6 \mathrm{~nm}$, spherical), followed by polyvinylpyrrolidone-coated Ag-NPs ( $\sim 9 \mathrm{~nm}$, spherical) and citrated-coated Ag-NP ( 60 nm, spherical and rods). The particles used in the study were relatively well characterized, including DLS, zeta potential and measurement of $\mathrm{Ag}+$ release in the dispersion state. ICP-MS measurements of Ag uptake in plant material improved the understanding of results. The high toxicity of CTAB-coated Ag-NP was attributed to the small size and strong positive surface charge. Cvjetko et al.[66] also reported the genotoxicity of Ag-NPs and $\mathrm{AgNO}_{3}$ in $N$. tabacum root and leaf by using comet assay. The authors observed accumulation of Ag for both Ag-NPs and $\mathrm{AgNO}_{3}$, with high accumulation in root. Higher toxicity was observed for $\mathrm{AgNO}_{3}$ than $\mathrm{Ag}$ NPs $\left(R F\right.$ com Ag-NPs $\left.=1.18<\mathrm{AgNO}_{3}=2.05\right)$. However, a major drawback of both studies was the presentation of concentrations in molar units of particles, traditionally used for soluble chemicals.

Most of the studies discussed so far used commercially available Ag-NPs, but Panda et al.[67] used biologically synthesized Ag-NPs. Plant broth from several plant materials (including Pungamia pinnata, Hemidesmus indicus, Syzygium cumini) was used in the production of the Ag-NP (Ag-NPp). The NPs produced was characterized by UV-vis spectral analysis, Fourier transform infrared, and TEM-EDX. The study design used A. cepa bulbs exposed to several controls, including $\mathrm{Ag}+$ ion $\left(\mathrm{AgNO}_{3}\right)$, colloidal $\mathrm{Ag}$ chloride $(\mathrm{AgCl})$, and commercially available Ag-NPs (Sigma, <100 nm) for comparison and better understanding. The results of comet, $\mathrm{CA}$ and $\mathrm{MN}$ assays indicated similar toxicity for the biosynthesized $\mathrm{Ag}$ NPp $(R F c o m=4.5 ; R F m n=\sim 7 ; R F c a=\sim 18)$ and the commercially available Ag-NPs (RFcom =4.6). The authors also demonstrated the role of oxidative stress and the protective role of free radical scavenging compounds Tiron and dimethyl thiourea on DNA damage. The study showed higher genotoxicity for $\mathrm{Ag}+$ ion than $\mathrm{Ag}-\mathrm{NPs}$, and colloidal $\mathrm{AgCl}$ was the least toxic.

On the basis of most of these studies, Ag-NPs and Ag+ ion seem to induce oxidative stress. Additionally, most of the studies revealed genotoxicity in a wide range of plant systems (A. cepa, N. tabacum, V. faba). However, the effect of dispersion/exposure conditions and 
surface modification needs further investigation. Adding to this complexity is certainly the nature of exposure media (solid, semisolid, hydroponics), which has not been reported.

\subsection{Carbon nanotubes}

A relatively large number of studies have evaluated the effect of CNTs on seed germination and plant growth, but only 3 could be selected for the present review. Studies by our group $[21,68]$ were performed in $A$. cepa by using chromosome aberration and micronucleus assays. In both of these studies, a single form of MWCNT was used. The studies described the particle in its primary state and stock dispersion, but both did not provide characterization in the experimental condition. In the earlier study [68], we observed an increase in CA (RFca= 5.2) and MN $(R F m n=6.79)$ along with a decrease in MI. Results of comet and DNA diffusion assays confirmed the genotoxicity results. This was one of the first studies to report the genotoxicity of MWCNT in plants, but it had several design flaws, including the absence of proper characterization during exposure, insufficient number of cells scored, and absence of uptake. The later study [21] also reported an increase in CA $(R F c a=5)$ and $\mathrm{MN}(R F m n=20)$ but a lower concertation than the previous study. An increase in DNA damage was observed by comet assay and was associated with changes in cell cycle progression. Genomic instability was also evident from the results of random amplification of polymorphic DNA PCR (RAPDPCR). The study also provided the first of evidence of changes in DNA hypermethylation. This study [21] considerably improved upon the previous publication [68] by including information on NP uptake, but additional information on characterization was desirable. Andrade et al. [69] also reported the toxicity of MWCNT synthesized by the authors. Seeds of A. cepa were exposed to MWCNT dispersed in phosphate buffered saline in Petri plates for approximately 5 days. However, important issues limit the interpretation and comparison of the results. Characterization of MWCNT in exposure conditions was not provided. Also, the effective concentration of exposure might be affected by using filter paper for exposure in Petri plates. In the reported condition, no significant increase in CA or MN was observed. From the limited number of studies, all performed in A. cepa, genotoxicity of MWCNT was observed. However, no reports were available for single-walled CNTs, which must be performed.

\subsection{Titanium dioxide NPS}

$\mathrm{TiO}_{2}$-NPs are found in a wide variety of food and personal care products and hence are among the more well-studied NPs in animal test systems. However, fewer studies are available for genotoxicity in plant models possibly because of the limited use in plants, but contamination from manufacturing waste should be considered. One of the earlier studies on $\mathrm{TiO}_{2}-\mathrm{NPs}$ 
(mixture of rutile and anatase, primary size: $100 \mathrm{~nm}$, surface area: $14.0 \mathrm{~m}^{2} \mathrm{~g}^{-1}$ ) from our group[18] investigated genotoxicity in A. cepa and N. tabacum. Comet assay in both test systems confirmed the genotoxicity of $\mathrm{TiO}_{2}-\mathrm{NPs}($ RFcom, A. cepa $=\sim 6.5 ; N$. tabacum $=\sim 4$ ). Results of assays of MN (RFmn > 200) and CA $($ RFca $=5.8)$ in A. cepa revealed similar findings. From the genotoxicity test results, a bell-shaped dose response was observed. The study reported genotoxicity by using multiple test systems and endpoints, but the lack of proper dispersion protocol, characterization and uptake limits the interpretation of results. Additionally, the study used molar units of particles to represent the concentration of NPs, conventionally used for soluble chemicals, which must be avoided.

In one of the better-designed studies, Pakrashi et al.[70] reported the toxicity of $\mathrm{TiO}_{2}-$ NPs in A. cepa by CA and comet assay. The $\mathrm{TiO}_{2}-\mathrm{NPs}$ were well characterized in the exposure condition (primary size: $<25 \mathrm{~nm}$; hydrodynamic diameter: 92-94 nm). The authors observed an increase in CA (including breaks, laggards and bridges), decrease in MI and increase in DNA damage by comet assay. An increase in number of MNs was reported, but results were only qualitative. The findings of the genotoxicity assay were supported by measurements of NP uptake for all tested concentrations. A dose-dependent increase in DNA damage was found associated with oxidative stress.

Castiglione et al. [71] reported the genotoxicity of $\mathrm{TiO}_{2}-\mathrm{NPs}(<100 \mathrm{~nm}$, from $0.2-4.0 \%)$ in $V$. narbonensis and Z. mays seeds. The authors observed an increase in \%CA (RFca, $V$. narbonensis $=6, Z$. mays $=4$ ) and a decrease in MI. An increase in MN was reported, but it was not presented quantitatively. No additional information on particle dispersion or uptake was included in the report. In a later study, Castiglione et al.[24] studied the genotoxicity of two types of $\mathrm{TiO}_{2}-\mathrm{NPs}$ (tetragonal crystals $<100 \mathrm{~nm}$; spherical shape $<10 \mathrm{~nm}$ ) by using $V$. faba CA assay. The toxicity of the NPs was compared to bulk $\mathrm{TiO}_{2}$ but was tested for only a single concentration, which was not characterized in the dispersion state. Ultrastructural alterations were observed for $\mathrm{TiO}_{2}$-NPs $(<100 \mathrm{~nm})$ and bulk particles accumulated in the cell vacuole. $\mathrm{TiO}_{2}$-NPs $(<100 \mathrm{~nm})$ and bulk material induced an increase in CA, but no changes were observed for $\mathrm{TiO}_{2}-\mathrm{NPs}(<10 \mathrm{~nm})$. The study also confirmed oxidative stress induced by the NPs in $V$. faba roots.

From these studies of the genotoxicity of $\mathrm{TiO}_{2}-\mathrm{NPs}$ in different plant systems including A. cepa and $V$. faba, both the Anatase-Rutile mixture $(\mathrm{n}=3)[18,24,71]$ and Anatase forms $(\mathrm{n}=1)$ [70] were found genotoxic on comet, CA and MN assays. However, most of these studies did 
not account for certain critical factors such as the differences between the crystal nature of $\mathrm{TiO}_{2}-\mathrm{NP}$ (Anatase, Rutile, Anatase-Rutile mixture) or photo activation, in addition to dispersion/uptake.

\subsection{Zinc NPs}

A few studies have addressed the genotoxicity of $\mathrm{ZnO}-\mathrm{NPs}$ in plant systems by mostly CA and MN assays. Kumari et al.[72] and Ghosh et al.[23] studied the same ZnO-NPs (primary size <100 nm, purity: 99.5\%, and surface area $15-25 \mathrm{~m}^{2} \mathrm{~g}^{-1}$ ). Both studies used bulk ZnO particles as additional controls. In addition to the primary particle characterization, Kumari et al.[72] measured the hydrodynamic diameter and $\mathrm{Zn}$ ion release for the test concentrations. The study reported an increase in genotoxicity in Allium root cells by assays of CA $(R F c a=\sim 400)$ and $\mathrm{MN}(R F m n=9.12)$. The high frequency of $\mathrm{MN}$ and CA was correlated with oxidative stress and internalization of ZnO NPs. The study by Ghosh et al.[23] used multiple plant systems to study the genotoxicity. The clastogenic/aneugenic effects were studied by using CA/MN assays in established models, A. cepa and V. faba. Comet assay was used to study DNA fragmentation in A. cepa and $N$. tabacum. The particles were relatively well characterized, reporting primary characterization (TEM, SEM-EDX) in addition to DLS measurements and dissolution at the exposure concentrations. All test systems revealed an increase in genotoxicity, oxidative stress, G2/M cell cycle arrest, and gross ultrastructural alterations associated with ZnO-NP uptake and accumulation. The study is unique in reporting genotoxicity by using multiple model plant systems, but it used significantly higher concentrations than what may be environmentally relevant. Taranath et al.[73] reported the genotoxicity of Zn-NPs biosynthesized by using Justicia adhatoda leaf extract. The synthesized primary particles were well characterized, but no characterization was reported for the dispersion. Additionally, the NPs were prepared in percentages of stock solution and absolute concentrations were not reported. The authors reported an increase in CA and decrease in MI in A. cepa root cells, but the lack of statistical representation did not allow for further interpretation. Despite the limited number of studies, all confirmed the genotoxicity of ZnO-NPs in plants (A. cepa/V. faba). However, similar to studies for other NPs, these studies provide only limited understanding of ZnO-NP toxicity, mostly lacking information on dissolution and/or uptake.

\subsection{Aluminum oxide NPs}

As compared with the previously discussed NPs, the genotoxicity of $\mathrm{Al}_{2} \mathrm{O}_{3}-\mathrm{NPs}$ is relatively less studied. Rajeshwari et al. [74] reported the genotoxic effect of $\mathrm{Al}_{2} \mathrm{O}_{3}-\mathrm{NPs}(<50$ nm; Sigma Aldrich, USA) in A. серa. The results of CA assay were well supported by proper 
characterization, results of oxidative stress and internalization of particles. The particles induced a significant dose-dependent decrease in MI and an increase in \%CA $(R F c a>130)$ from 0.01 to $100 \mu \mathrm{g} / \mathrm{ml}$. A later study by De et al.[75] reported similar findings for the same $\mathrm{Al}_{2} \mathrm{O}_{3}$-NPs ( $<50 \mathrm{~nm}$; Sigma Aldrich, USA) in A. cepa. The authors observed a decrease in MI and an increase in CA $(R F c a=12.1)$ and micronuclei formation $(R F m n>200)$ with a 0 - to 5$\mu \mathrm{M}$ dose. The authors also reported an increase in \%tail DNA $(R F \operatorname{com}=\sim 5)$ as observed by comet assay. This study is also important because it compared the effect of $\mathrm{Al}_{2} \mathrm{O}_{3}-\mathrm{NPs}$ with that of $\mathrm{Al}_{2} \mathrm{O}_{3}$ bulk particles in the same concentration range and observed higher toxicity of the nano form. The increase in DNA damage was attributed to increased oxidative stress. Despite a good design, the study was limited by the lack of NP uptake measurements and representation of treatment concentration in molar units.

\subsection{Other NPs}

Nagaonkar et al.[76] reported the toxicity of Cu-NPs in A. cepa. The authors reported the DLS ("5 51 of colloidal CuNP solution with $2 \mathrm{ml}$ distilled water") and zeta potential ("30 $\mu 1$ of colloidal NP sample with $2 \mathrm{ml}$ distilled water"), but measurements were not performed in the same condition and are not representative of the exposure conditions. The tested concentration conferred a decrease in MI and increase in CA, but insufficient numbers of cells were scored (500-600), and lack of clear representation of statistical analysis limits the interpretation. However, synthesized $\mathrm{Cu}$-NPs were more toxic than the $\mathrm{Cu}$ ion, as the control.

Faisal et al.[77] described the genotoxicity of cobalt oxide NPs $\left(\mathrm{Co}_{3} \mathrm{O}_{4}-\mathrm{NPs}\right.$, Sigma Aldrich, USA), together with oxidative stress, mitochondrial dysfunction and cell cycle progression in Solanum melongena seeds. Several concentrations were used, but in our opinion, the concentrations used were much higher (up to $1 \mathrm{mg} / \mathrm{ml}$ ) than would be environmentally relevant. Additionally, DLS and zeta potential measurements were performed at $10 \mu \mathrm{g} / \mathrm{ml}$, which is not representative of the concentrations used in the study (lowest dose used: 0.025 $\mathrm{mg} / \mathrm{ml}$ or $25 \mu \mathrm{g} / \mathrm{ml}$ ). Uptake of NPs was observed on TEM and an increase in Olive tail moment was observed for the treatment concentrations.

The phytotoxic effect of NiO-NPs in tomato was reported by Faisal et al.[78], who evaluated DNA damage by comet assay along with other oxidative stress parameters. The studies considered the dissolution of $\mathrm{Ni}$ ion, now established as a critical determinant in $\mathrm{NiO}-$ NP-induced toxicity from animal studies. The publication reported an increase in apoptotic/necrotic cells, but the results of comet assay (\%tail DNA) were not presented 
quantitatively. NiO-NPs were studied in A. cepa and other Allium species (A. fistulosum, A. schoenoprasum, A. sativum, A. porrum) by using a series of cyto-genotoxicity and oxidative stress endpoints[79]. The study reported CA/MN in multiple Allium species but gave insufficient information on chromosome numbers/ploidy. The study considered NiO-NP characterization in the stock dispersion by using DLS and zeta potential, and Ni uptake in plant tissues was measured by ICP. The authors observed a decrease in MI and an increase in MN and CA in all species tested, with the highest genotoxic effect observed at $125 \mathrm{mg} / \mathrm{L}$. The study would have additionally benefited from measurement of dissolution for the tested concentrations and better-defined scoring criteria for $\mathrm{MN}$.

Rajeshwari et al.[80] studied the cytogenetic effect of CTAB and polyethylene glycol (PEG)-capped gold nanorods (Au-NRs) by using an Allium test. The study used wellcharacterized CTAB-capped Au-NRs and PEG-capped Au-NRs at 0.1, 1, and $10 \mu \mathrm{g} / \mathrm{mL}$ dispersed in water. However, it did not characterize particles at the individual experimental concentration. The results indicated a decrease in $\mathrm{MI}$ and an increase in \%CA for the CTABcapped Au-NRs $(R F c a=163)$, whereas for PEG-capped Au-NRs, the change in MI and \%CA $(R F c a=31)$ was lower. The results showed higher toxicity of CTAB-capped Au-NR than PEGcapped Au-NRs, but the use of pristine Au-NPs would have provided a better understanding of the effect of surface capping. Additionally, the study would have benefited from the measurement of NP uptake. Rajeshwari et al. [81] studied the effect of different sizes of citratecapped Au-NPs (Au15- 15 nm, Au30- 30 nm, Au40- 40 nm). The citrate-capped particles were tested for genotoxicity by using an Allium test and citrate as controls. The results indicated clear association between the genotoxicity and smaller size of Au-NPs $(R F c a$ Au15 = $21.7>$ Au30 $=18.8>\mathrm{Au} 40=16.2$ ). Oxidative stress induced by Au-NPs in root cells were also observed. However, information on NP uptake was not provided.

The genotoxic effect of ferric oxide nanoparticles $\left(\mathrm{Fe}_{2} \mathrm{O}_{3}-\mathrm{NPs}\right)$ was reported in Raphanus sativus by comet assay [82].The NPs were well characterized in the primary state (TEM: $22.3 \pm 3.1 \mathrm{~nm}$; atomic force microscopy: $26 \pm 2.8 \mathrm{~nm}$ ) and in the dispersion state for the stock concentration (hydrodynamic diameter: $271 \pm 2.4 \mathrm{~nm}$, zeta potential: $-4.1 \pm 0.9 \mathrm{mV}$ ). Ultrathin sections confirmed the uptake and localization of $\mathrm{Fe}_{2} \mathrm{O}_{3}-\mathrm{NPs}$, along with damaged mitochondria and altered mitochondrial membrane potential, oxidative stress and extensive vacuolation. Comet assay showed a dose-dependent increase in DNA damage $(R F c o m=4.3)$. However, the percentage of the "sub G1" population mentioned was much higher than expected 
from the comet assay results. In this case, it might be important to measure the percentage of apoptotic cells from the comet assay itself or use DNA diffusion assay.

The comet assay and Allium test has been used to study genotoxicity of inidium tin oxide [ITO; Indium (III) oxide $\left(\mathrm{In}_{2} \mathrm{O}_{3}, 90 \%\right)$ and tin (IV) oxide $\left(\mathrm{SnO}_{2}, 10 \%\right)$ ]. One study [83] used ITO $(<50 \mathrm{~nm})$ in the hydroponic condition, which resulted in increased MI, \%CA $(R F c a=1.89)$ and comet assay findings $(R F$ com $=3.06)$. However, it did not report characterization of particles in the hydroponic condition used for the experiment, nor did it provide information on the NP uptake. CA in roots from A. cepa seeds were studied for chitosan NPs loaded with paraquat [84]. The stability was well characterized for the particle. The authors observed reduced toxicity of paraquat when encapsulated inside the chitosan NP. The study included proper characterization of the particle synthesized, but the number of cells scored (700/replicate) were relatively lower than recommended. Additional information on NP uptake would have improved the interpretation. Nevertheless, the study used suitable controls, which allows for proper interpretation of the results.

Despite their large-scale release into the environment and controversial phytotoxicity, the genotoxicity of cerium oxide NPs (Ce-NPs) is rarely studied in plant systems. In a pioneer study, López-Moreno et al. [85] investigated the genotoxicity of Ce-NPs (0, 500, 1000, 2000 and $4000 \mathrm{mg} \mathrm{L}^{-1}$ in water) in Glycine max seedlings. Despite the primary characterization, the particles were not characterized in suspension under the exposure conditions. The seedlings were treated for 1 week and assessed for genotoxicity by using RAPD-PCR. Results showed new bands at the higher concentrations of 2000 and $4000 \mathrm{mg} \mathrm{L}^{-1}$, signifying a genotoxic response. This finding was attributed to maximum uptake at the highest concentration as studied by ICP-optical emission spectrometry. However, the interpretation of results by RAPD-PCR is rather qualitative because no other confirmatory quantitative genotoxicity tests were performed. Later, Mattiello et al. [86] reported the genotoxicity of Ce-NPs in $H$. vulgare seedlings by using RAPD-PCR and MI. Germinated seedlings were exposed to aqueous dispersions of the NP ( 0 , 500,1000 , and $2000 \mathrm{mg} \mathrm{L}^{-1}$ in water) for $24 \mathrm{~h}$. The NPs were properly characterized for primary features and hydrodynamic size, charge and PDI, at $1000 \mathrm{mg} \mathrm{L}^{-1}$ in water, although no information on the changes in physicochemical characters after treatment was provided. Reduced MI was reported at $2000 \mathrm{mg} \mathrm{L}^{-1} \mathrm{Ce}-\mathrm{NPs}$. This was supported by maximum variability in RAPD banding pattern at the same concentration. Qualitative assessment of internalization by TEM showed Ce-NP clusters in the cortical parenchymal tissues and xylem of root cells. However, MI revealed only a reduced frequency of cell division, which can be better associated 
with cytotoxicity. Furthermore, cytological studies with parameters such as MN, CA and NA are required to fully understand the effect of Ce-NPs at the chromosomal level. In a recent in vitro study of tobacco BY-2 cells, Sadhu et al. [87] reported Ce-NP-induced DNA damage at a high concentration $\left(250 \mathrm{mg} \mathrm{L}^{-1}\right)$ and autophagy-mediated anti-genotoxicity against $\mathrm{H}_{2} \mathrm{O}_{2}$ challenge at a low concentration $\left(10 \mathrm{mg} \mathrm{L}^{-1}\right)$ by comet assay. The study involved proper physicochemical characterization of CeNP in powdered form and in exposure media along with quantitative assessment of adsorption/internalization. Dissolution of $\mathrm{Ce}$ ion at exposure concentrations was also provided. Moreover, the authors used culture media devoid of chelating agents. The study also provided a reproducible protocol for comet assay with tobacco BY-2 cells for nanotoxicity analyses. To our knowledge, no other reports are available on the in planta genotoxicity of this abundantly dissipated nanomaterial. Because most nanotoxicity studies of Ce-NPs are performed with edible plants and focus on their phytotoxicity and/or fate, their genotoxicity should be studied in model plants with quantitative parameters.

One of the better-designed studies using plant-based genotoxicity assays examined nZVI particles (nZVI-1 and nZVI-2) in A. cepa [36]. The study incorporated characterization of the primary particle together with characterization at all exposure concentrations over the duration of the experiment ( 0 and $24 \mathrm{~h})$. The study also considered the dissolution and uptake of particles along with adsorption and morphological alterations. Adsorption of nZVI was associated with epidermal and root hair damage. An ultrastructural study showing cellular internalization and biodistribution would have added visual insights to support the above data. Of the two particles tested, nZVI-1 induced higher genotoxicity than nZVI-2. These particles also induced oxidative stress leading to membrane lipid peroxidation, electrolyte leakage and mitochondrial depolarisation. The authors also showed the occurrence of programmed cell death because of nZVI-induced DNA fragmentation. The results provide significant new information on the toxicity of nZVI and importantly presented a suitable study design, which could be followed.

\section{Summary and recommendations}

In total, 29 studies reported the genotoxicity of different NPs, mostly performed in the model plants Allium sp $(n=22)$, Nicotiana sp $(n=4)$, and Vicia sp $(n=4)$ and commonly used ecotoxicity testing (Fig 3). Most of these studies used hydroponic exposure conditions $(n=20)$ and exposure in Petri plates $(n=7)$. As discussed earlier, none of the studies evaluated the effect of exposure media/soil. Genotoxicity was mostly evaluated by using CA assays $(n=22)$, along with 
MN (n=15) and comet assays ( $n=14)$. A few studies also used RAPD analysis, not discussed in detail here. Genotoxicity was observed for most of the reported studies.

\section{<Figure 3>}

Most of the studies discussed did not consider certain aspects that are essential for nanotoxicology studies. The quality score for each of the studies highlights the need for improved study design and scoring criteria and an emphasis on particle characterization and uptake. However, most of the studies published after 2014 obtained a higher average score.

Assay methods and scoring criteria used in each of the studies affected the results and therefore significantly affected the quality score. In many of the publications, an insufficient number of cells was examined for a conclusion. In addition, the criteria used for scoring and presenting the results were not uniform among the studies. Discussing the technicalities of scoring used for each of the assays is beyond the scope of this review, but we briefly highlight the common errors we observed as follows:

- Significantly higher MI (often > 60-70), not clearly defining how results have been presented. Studies should state clearly whether MI is presented as cells in mitosis/1000 cells or calculated with the more accepted standard formula [(number of cells in mitosis/total number of cells) $\mathrm{x} 100]$.

- Scoring of nuclear buds/artefacts as micronucleus

- Incorrect identification of nuclear/chromosomal aberrations including c-mitosis, laggard and vagrants

- Mistakenly identifying late telophase or interphase nuclei of A. cepa, which often show two nucleoli per nucleus [88], as binucleate cells.

The scoring revealed that earlier studies, which often lacked proper characterization of materials and information on uptake/localization, had a lower score than newer studies. Many of these studies did not report characterization of particles in the exposure conditions and others did not use suitable controls. We found lack of uniform/standard methods, which might affect the assay outcome. From our understanding of nanotoxicology, based on some studies in plants and mostly those performed in animal cells in vitro, factors that might affect assay outcome and the interpretation must be properly defined and controlled for.

From the above discussion and our observations, we suggest some basic recommendations that should be considered when reporting NP toxicity in plants. 
- Characterization of primary particle: Report the primary size, shape, surface area and purity of the particle. Moreover, if applicable, the size of bulk aggregates should be provided.

- Well-defined dispersion protocol: The use of surfactant/solvent/dispersion media and sonication conditions should be clearly described. The process by which exposure conditions are obtained from stock solution should be clearly mentioned. Any surfactant/solvent/dispersion media used should be a vehicle control for the experiment. The use of liquid media is prevalent in plant nanotoxicity studies involving long-term exposure. For metal NPs, the presence of chelating agents (eg, $\left.\mathrm{P}_{\mathrm{i}}-\mathrm{EDTA}-\mathrm{FeSO}_{4}\right)$ in the medium enhances agglomeration/aggregation. Such media components should be avoided as much as possible.

- Characterization of NPs in exposure conditions: DLS/zeta potential and if possible sedimentation of particles must be measured in the exposure condition. These measurements are critical to determine effective exposure concentrations. Additionally, dissolution of metal NPs must be considered.

- Medium of exposure: Mostly hydroponic exposure is used in genotoxicity studies, but any exception should be supported by information on NP-exposure media interaction. This is important because mobility and behaviour of particles is greatly affected by the components of exposure media.

- Concentration selection: Most studies involved high concentrations of NPs. An understanding of the genotoxicity of NPs at a wide range of concentrations is important, but the use of environmentally relevant exposure concentrations is highly recommended.

- Uptake of NPs: Toxicity results must be complemented with results of NP uptake. They could be qualitative, by using TEM (for CNTs), or quantitative, by using ICP (for metal NPs) or both.

- Use of proper scoring criteria: Often in experiments, a fewer number of cells than required were scored for CA, MN and comet assays. We recommend a minimum of 1000 cells/root in triplicate $(1000 \times 3)$ be scored for $\mathrm{MI}$ and $\mathrm{CA}$ and $\mathrm{MN}$ assays. For anaphase/telophase aberrations, a minimum of 500 cells/treatment condition should be scored. In addition, proper scoring criteria for aberration and micronucleus assay should be followed. Reference images for different kinds of aberrations, which may be used for proper scoring, are in the review by Leme and Marin-Morales[10] and could be used. For comet assay, 25-50 cells/replicate in triplicate (depending on the plant species and ease of nuclei isolation) per concentration must be scored. Authors should additionally consider possible interference in 
scoring, especially at high concentrations of NP exposure. Edge effect (formation of distorted comets due to drying at the edges of the gel) on comet slides should be considered to avoid false-positive results. Additional uncertainties arising due to scoring biases should be considered.

\section{References}

[1] A.A. Keller, W. Vosti, H. Wang, A. Lazareva, Release of engineered nanomaterials from personal care products throughout their life cycle, J. Nanoparticle Res. 16 (2014) 2489. doi:10.1007/s11051-014-2489-9.

[2] F. Gottschalk, B. Nowack, The release of engineered nanomaterials to the environment, J. Environ. Monit. 13 (2011) 1145. doi:10.1039/c0em00547a.

[3] Y. Wang, B. Nowack, Dynamic probabilistic material flow analysis of nano-SiO2, nano iron oxides, nano-CeO2, nano-A12O3, and quantum dots in seven European regions, Environ. Pollut. 235 (2018) 589-601. doi:10.1016/J.ENVPOL.2018.01.004.

[4] O. US EPA, Control of Nanoscale Materials under the Toxic Substances Control Act, (n.d.). https://www.epa.gov/reviewing-new-chemicals-under-toxic-substances-controlact-tsca/control-nanoscale-materials-under (accessed January 31, 2018).

[5] U. EPA Federal Facilities Restoration, R. Office, Technical Fact sheet Nanomaterials, (2011). https://www.epa.gov/sites/production/files/201403/documents/ffrrofactsheet_emergingcontaminant_nanomaterials_jan2014_final.pdf (accessed August 3, 2017).

[6] A. Mukherjee, T. Gichner, Research Methods in Plant Sciences: Allelopathy (Eds: D. A. Sampietro and S. S. Narwal), Studium Press, LLC. Houston,Texas, USA | Institute of Experimental Botany AS CR, in: D. A. Sampietro and S. S. Narwal (Ed.), Res. Methods Plant Sci. Allelopath., Studium Press, LLC. Houston,Texas, USA, 2009: pp. 97-108. http://www.ueb.cas.cz/en/category/source-titles/research-methods-plantsciences-allelopathy-eds-d-sampietro-and-s-s-narwal (accessed August 3, 2017).

[7] W.F. Grant, The present status of higher plant bioassays for the detection of environmental mutagens, Mutat. Res. Mol. Mech. Mutagen. 310 (1994) 175-185. doi:10.1016/0027-5107(94)90112-0.

[8] M. Iqbal, Vicia faba bioassay for environmental toxicity monitoring: A review, Chemosphere. 144 (2016) 785-802. doi:10.1016/J.CHEMOSPHERE.2015.09.048.

[9] A. K. Patlolla, Environmental Toxicity Monitoring of Nanomaterials using Vicia Faba GENE-TOX Assay, J. Nanomed. Nanotechnol. 04 (2013) 1-3. doi:10.4172/2157$7439.1000 \mathrm{e} 129$.

[10] D.M. Leme, M.A. Marin-Morales, Allium cepa test in environmental monitoring: A review on its application, Mutat. Res. Mutat. Res. 682 (2009) 71-81. doi:10.1016/j.mrrev.2009.06.002.

[11] T.-H. Ma, Vicia cytogenetic tests for environmental mutagens: A report of the U.S. environmental protection agency Gene-Tox program, Mutat. Res. Genet. Toxicol. 99 (1982) 257-271. doi:10.1016/0165-1110(82)90045-8.

[12] T.-H. Ma, Z. Xu, C. Xu, H. McConnell, E. Valtierra Rabago, G. Adriana Arreola, H. Zhang, The improved Allium/Vicia root tip micronucleus assay for clastogenicity of environmental pollutants, Mutat. Res. Mutagen. Relat. Subj. 334 (1995) 185-195. doi:10.1016/0165-1161(95)90010-1.

[13] W.F. Grant, Chromosome aberration assays in allium: A report of the U.S. environmental protection agency gene-tox program, Mutat. Res. Genet. Toxicol. 99 
(1982) 273-291. doi:10.1016/0165-1110(82)90046-X.

[14] T.-H. Ma, G.L. Cabrera, E. Owens, Genotoxic Agents Detected by Plant Bioassays, Rev. Environ. Health. 20 (2005) 1-14. doi:10.1515/REVEH.2005.20.1.1.

[15] S. Knasmüller, E. Gottmann, H. Steinkellner, A. Fomin, C. Pickl, A. Paschke, R. Göd, M. Kundi, Detection of genotoxic effects of heavy metal contaminated soils with plant bioassays, Mutat. Res. Toxicol. Environ. Mutagen. 420 (1998) 37-48. doi:10.1016/S1383-5718(98)00145-4.

[16] G.. Cabrera, D.M.. Rodriguez, Genotoxicity of soil from farmland irrigated with wastewater using three plant bioassays, Mutat. Res. Mol. Mech. Mutagen. 426 (1999) 211-214. doi:10.1016/S0027-5107(99)00070-6.

[17] I. Ghosh, M. Ghosh, A. Mukherjee, M. Ghosh, A. Mukherjee, Methods of In Vitro and In Vivo Nanotoxicity Evaluation in Plants, in: Environ. Toxic. Nanomater., CRC Press, 2018: pp. 281-304. doi:10.1201/9781351252966-11.

[18] M. Ghosh, M. Bandyopadhyay, A. Mukherjee, Genotoxicity of titanium dioxide (TiO2) nanoparticles at two trophic levels: Plant and human lymphocytes, Chemosphere. 81 (2010) 1253-1262. doi:10.1016/j.chemosphere.2010.09.022.

[19] R. Kaveh, Y.-S. Li, S. Ranjbar, R. Tehrani, C.L. Brueck, B. Van Aken, Changes in Arabidopsis thaliana Gene Expression in Response to Silver Nanoparticles and Silver Ions, Environ. Sci. Technol. 47 (2013) 10637-10644. doi:10.1021/es402209w.

[20] A.K. Patlolla, A. Berry, L. May, P.B. Tchounwou, Genotoxicity of silver nanoparticles in Vicia faba: a pilot study on the environmental monitoring of nanoparticles., Int. J. Environ. Res. Public Health. 9 (2012) 1649-62. doi:10.3390/ijerph9051649.

[21] M. Ghosh, S. Bhadra, A. Adegoke, M. Bandyopadhyay, A. Mukherjee, MWCNT uptake in Allium cepa root cells induces cytotoxic and genotoxic responses and results in DNA hyper-methylation, Mutat. Res. Mol. Mech. Mutagen. 774 (2015) 49-58. doi:10.1016/j.mrfmmm.2015.03.004.

[22] M. Ghosh, M. J, S. Sinha, A. Chakraborty, S.K. Mallick, M. Bandyopadhyay, A. Mukherjee, In vitro and in vivo genotoxicity of silver nanoparticles, Mutat. Res. Toxicol. Environ. Mutagen. 749 (2012) 60-69. doi:10.1016/j.mrgentox.2012.08.007.

[23] M. Ghosh, A. Jana, S. Sinha, M. Jothiramajayam, A. Nag, A. Chakraborty, A. Mukherjee, A. Mukherjee, Effects of $\mathrm{ZnO}$ nanoparticles in plants: Cytotoxicity, genotoxicity, deregulation of antioxidant defenses, and cell-cycle arrest, Mutat. Res. Genet. Toxicol. Environ. Mutagen. 807 (2016). doi:10.1016/j.mrgentox.2016.07.006.

[24] M. Ruffini Castiglione, L. Giorgetti, L. Bellani, S. Muccifora, S. Bottega, C. Spanò, Root responses to different types of $\mathrm{TiO} 2$ nanoparticles and bulk counterpart in plant model system Vicia faba L., Environ. Exp. Bot. 130 (2016) 11-21. doi:10.1016/J.ENVEXPBOT.2016.05.002.

[25] G.B. dos Reis, L.F. Andrade-Vieira, I. de C. Moraes, P.H.S. César, S. Marcussi, L.C. Davide, Reliability of plant root comet assay in comparison with human leukocyte comet assay for assessment environmental genotoxic agents, Ecotoxicol. Environ. Saf. 142 (2017) 110-116. doi:10.1016/J.ECOENV.2017.04.004.

[26] M. Zhu, G. Nie, H. Meng, T. Xia, A. Nel, Y. Zhao, Physicochemical Properties Determine Nanomaterial Cellular Uptake, Transport, and Fate, Acc. Chem. Res. 46 (2013) 622-631. doi:10.1021/ar300031y.

[27] P.M. Winter, G.M. Lanza, S.A. Wickline, M. Madou, C. Wang, P.B. Deotare, M. Loncar, Y.K. Yap, J. Rose, M. Auffan, O. Proux, V. Niviere, J.-Y. Bottero, Z.L. Wang, Y. Liu, R.G. Polcawich, J.S. Pulskamp, R.M. Proie, W.-T. Park, S. V. Kalinin, B.J. Rodriguez, A.L. Kholkin, G.L. Liu, J. Lagemaat, L. Valdevit, J.W. Hutchinson, S. Oh, M. Madou, K. Tonisch, E. De Rosa, J. Fernandez-Moure, E. Tasciotti, D. Gebauer, B.E. O’Neill, K.C. Li, Physicochemical Properties of Nanoparticles in Relation with 
Toxicity, in: Encycl. Nanotechnol., Springer Netherlands, Dordrecht, 2012: pp. 20852085. doi:10.1007/978-90-481-9751-4_334.

[28] K.L. Aillon, Y. Xie, N. El-Gendy, C.J. Berkland, M.L. Forrest, Effects of nanomaterial physicochemical properties on in vivo toxicity, Adv. Drug Deliv. Rev. 61 (2009) 457466. doi:10.1016/J.ADDR.2009.03.010.

[29] M.A. Gatoo, S. Naseem, M.Y. Arfat, A.M. Dar, K. Qasim, S. Zubair, Physicochemical properties of nanomaterials: implication in associated toxic manifestations., Biomed Res. Int. 2014 (2014) 498420. doi:10.1155/2014/498420.

[30] K. Donaldson, C.A. Poland, Nanotoxicity: challenging the myth of nano-specific toxicity, Curr. Opin. Biotechnol. 24 (2013) 724-734. doi:10.1016/J.COPBIO.2013.05.003.

[31] R.Y. Prasad, K. Wallace, K.M. Daniel, A.H. Tennant, R.M. Zucker, J. Strickland, K. Dreher, A.D. Kligerman, C.F. Blackman, D.M. DeMarini, Effect of Treatment Media on the Agglomeration of Titanium Dioxide Nanoparticles: Impact on Genotoxicity, Cellular Interaction, and Cell Cycle, ACS Nano. 7 (2013) 1929-1942. doi:10.1021/nn302280n.

[32] G. Maiorano, S. Sabella, B. Sorce, V. Brunetti, M.A. Malvindi, R. Cingolani, P.P. Pompa, Effects of Cell Culture Media on the Dynamic Formation of Protein-Nanoparticle Complexes and Influence on the Cellular Response, ACS Nano. 4 (2010) 7481-7491. doi:10.1021/nn101557e.

[33] I. Römer, A.J. Gavin, T.A. White, R.C. Merrifield, J.K. Chipman, M.R. Viant, J.R. Lead, The critical importance of defined media conditions in Daphnia magna nanotoxicity studies, Toxicol. Lett. 223 (2013) 103-108. doi:10.1016/J.TOXLET.2013.08.026.

[34] B. Halamoda-Kenzaoui, M. Ceridono, P. Colpo, A. Valsesia, P. Urbán, I. OjeaJiménez, S. Gioria, D. Gilliland, F. Rossi, A. Kinsner-Ovaskainen, Dispersion Behaviour of Silica Nanoparticles in Biological Media and Its Influence on Cellular Uptake, PLoS One. 10 (2015) e0141593. doi:10.1371/journal.pone.0141593.

[35] US-EPA, Nanotechnology for Site Remediation Fact Sheet (EPA 542-F-08-009), n.d. https://semspub.epa.gov/work/HQ/160619.pdf (accessed February 21, 2018).

[36] I. Ghosh, A. Mukherjee, A. Mukherjee, In planta genotoxicity of nZVI: influence of colloidal stability on uptake, DNA damage, oxidative stress and cell death, Mutagenesis. 32 (2017) 371-387. doi:10.1093/mutage/gex006.

[37] M. Bhuvaneshwari, D. Kumar, R. Roy, S. Chakraborty, A. Parashar, A. Mukherjee, N. Chandrasekaran, A. Mukherjee, Toxicity, accumulation, and trophic transfer of chemically and biologically synthesized nano zero valent iron in a two species freshwater food chain, Aquat. Toxicol. 183 (2017) 63-75. doi:10.1016/J.AQUATOX.2016.12.013.

[38] C. Levard, E.M. Hotze, G. V. Lowry, G.E. Brown, Environmental Transformations of Silver Nanoparticles: Impact on Stability and Toxicity, Environ. Sci. Technol. 46 (2012) 6900-6914. doi:10.1021/es2037405.

[39] Z.-Q. Tan, Y.-G. Yin, X.-R. Guo, M. Amde, M.H. Moon, J.-F. Liu, G.-B. Jiang, Tracking the Transformation of Nanoparticulate and Ionic Silver at Environmentally Relevant Concentration Levels by Hollow Fiber Flow Field-Flow Fractionation Coupled to ICPMS, Environ. Sci. Technol. 51 (2017) 12369-12376. doi:10.1021/acs.est.7b03439.

[40] T. Xia, M. Kovochich, M. Liong, L. Mädler, B. Gilbert, H. Shi, J.I. Yeh, J.I. Zink, A.E. Nel, Comparison of the Mechanism of Toxicity of Zinc Oxide and Cerium Oxide Nanoparticles Based on Dissolution and Oxidative Stress Properties, ACS Nano. 2 (2008) 2121-2134. doi:10.1021/nn800511k. 
[41] J.E. Eixenberger, C.B. Anders, R.J. Hermann, R.J. Brown, K.M. Reddy, A. Punnoose, D.G. Wingett, Rapid Dissolution of ZnO Nanoparticles Induced by Biological Buffers Significantly Impacts Cytotoxicity, Chem. Res. Toxicol. 30 (2017) 1641-1651. doi:10.1021/acs.chemrestox.7b00136.

[42] L. Vittori Antisari, S. Carbone, A. Gatti, G. Vianello, P. Nannipieri, Uptake and translocation of metals and nutrients in tomato grown in soil polluted with metal oxide $(\mathrm{CeO} 2, \mathrm{Fe} 3 \mathrm{O} 4, \mathrm{SnO} 2, \mathrm{TiO} 2)$ or metallic $(\mathrm{Ag}, \mathrm{Co}, \mathrm{Ni})$ engineered nanoparticles, Environ. Sci. Pollut. Res. 22 (2015) 1841-1853. doi:10.1007/s11356-014-3509-0.

[43] X. Gui, Z. Zhang, S. Liu, Y. Ma, P. Zhang, X. He, Y. Li, J. Zhang, H. Li, Y. Rui, L. Liu, W. Cao, Fate and Phytotoxicity of $\mathrm{CeO} 2$ Nanoparticles on Lettuce Cultured in the Potting Soil Environment., PLoS One. 10 (2015) e0134261. doi:10.1371/journal.pone.0134261.

[44] T.K. Darlington, A.M. Neigh, M.T. Spencer, O.T. Nguyen, S.J. Oldenburg, NANOPARTICLE CHARACTERISTICS AFFECTING ENVIRONMENTAL FATE AND TRANSPORT THROUGH SOIL, Environ. Toxicol. Chem. 28 (2009) 1191. doi:10.1897/08-341.1.

[45] P.S. Tourinho, C.A.M. van Gestel, S. Lofts, C. Svendsen, A.M.V.M. Soares, S. Loureiro, Metal-based nanoparticles in soil: Fate, behavior, and effects on soil invertebrates, Environ. Toxicol. Chem. 31 (2012) 1679-1692. doi:10.1002/etc.1880.

[46] G. Cornelis, K. Hund-Rinke, T. Kuhlbusch, N. van den Brink, C. Nickel, Fate and Bioavailability of Engineered Nanoparticles in Soils: A Review, Crit. Rev. Environ. Sci. Technol. 44 (2014) 2720-2764. doi:10.1080/10643389.2013.829767.

[47] M. Khodakovskaya, E. Dervishi, M. Mahmood, Y. Xu, Z. Li, F. Watanabe, A.S. Biris, Carbon Nanotubes Are Able To Penetrate Plant Seed Coat and Dramatically Affect Seed Germination and Plant Growth, ACS Nano. 3 (2009) 3221-3227. doi: 10.1021/nn900887m.

[48] D. Cui, P. Zhang, Y. Ma, X. He, Y. Li, J. Zhang, Y. Zhao, Z. Zhang, Effect of cerium oxide nanoparticles on asparagus lettuce cultured in an agar medium, Environ. Sci. Nano. 1 (2014) 459-465. doi:10.1039/C4EN00025K.

[49] X. Yang, H. Pan, P. Wang, F.-J. Zhao, Particle-specific toxicity and bioavailability of cerium oxide $(\mathrm{CeO} 2)$ nanoparticles to Arabidopsis thaliana, J. Hazard. Mater. 322 (2017) 292-300. doi:10.1016/J.JHAZMAT.2016.03.054.

[50] W.-M. Lee, J. Il Kwak, Y.-J. An, Effect of silver nanoparticles in crop plants Phaseolus radiatus and Sorghum bicolor: Media effect on phytotoxicity, Chemosphere. 86 (2012) 491-499. doi:10.1016/J.CHEMOSPHERE.2011.10.013.

[51] F. Schwab, G. Zhai, M. Kern, A. Turner, J.L. Schnoor, M.R. Wiesner, Barriers, pathways and processes for uptake, translocation and accumulation of nanomaterials in plants - Critical review, Nanotoxicology. (2015) 1-22. doi:10.3109/17435390.2015.1048326.

[52] H. Zhu, J. Han, J.Q. Xiao, Y. Jin, Uptake, translocation, and accumulation of manufactured iron oxide nanoparticles by pumpkin plants, J. Environ. Monit. 10 (2008) 713. doi:10.1039/b805998e.

[53] Y. Ma, X. He, P. Zhang, Z. Zhang, Y. Ding, J. Zhang, G. Wang, C. Xie, W. Luo, J. Zhang, L. Zheng, Z. Chai, K. Yang, Xylem and Phloem Based Transport of $\mathrm{CeO}_{2}$ Nanoparticles in Hydroponic Cucumber Plants, Environ. Sci. Technol. 51 (2017) 5215-5221. doi:10.1021/acs.est.6b05998.

[54] R. Raliya, C. Franke, S. Chavalmane, R. Nair, N. Reed, P. Biswas, Quantitative Understanding of Nanoparticle Uptake in Watermelon Plants., Front. Plant Sci. 7 (2016) 1288. doi:10.3389/fpls.2016.01288.

[55] O. Zaytseva, Z. Wang, G. Neumann, Phytotoxicity of carbon nanotubes in soybean as 
determined by interactions with micronutrients, J. Nanoparticle Res. 19 (2017) 29. doi:10.1007/s11051-016-3722-5.

[56] X. Ma, J. Geiser-Lee, Y. Deng, A. Kolmakov, Interactions between engineered nanoparticles (ENPs) and plants: Phytotoxicity, uptake and accumulation, Sci. Total Environ. 408 (2010) 3053-3061. doi:10.1016/J.SCITOTENV.2010.03.031.

[57] S. Lin, J. Reppert, Q. Hu, J.S. Hudson, M.L. Reid, T.A. Ratnikova, A.M. Rao, H. Luo, P.C. Ke, Uptake, Translocation, and Transmission of Carbon Nanomaterials in Rice Plants, Small. 5 (2009) NA-NA. doi:10.1002/smll.200801556.

[58] B. Ahmed, S. Dwivedi, M.Z. Abdin, A. Azam, M. Al-Shaeri, M.S. Khan, Q. Saquib, A.A. Al-Khedhairy, J. Musarrat, Mitochondrial and Chromosomal Damage Induced by Oxidative Stress in $\mathrm{Zn}(2+)$ Ions, $\mathrm{ZnO}-$ Bulk and $\mathrm{ZnO}-\mathrm{NPs}$ treated Allium cepa roots., Sci. Rep. 7 (2017) 40685. doi:10.1038/srep40685.

[59] J.-H. Kim, Y. Lee, E.-J. Kim, S. Gu, E.J. Sohn, Y.S. Seo, H.J. An, Y.-S. Chang, Exposure of Iron Nanoparticles to Arabidopsis thaliana Enhances Root Elongation by Triggering Cell Wall Loosening, Environ. Sci. Technol. 48 (2014) 3477-3485. doi:10.1021/es4043462.

[60] M. Ghosh, A. Jana, S. Sinha, M. Jothiramajayam, A. Nag, A. Chakraborty, A. Mukherjee, A. Mukherjee, Effects of $\mathrm{ZnO}$ nanoparticles in plants: Cytotoxicity, genotoxicity, deregulation of antioxidant defenses, and cell-cycle arrest, Mutat. Res. Toxicol. Environ. Mutagen. 807 (2016) 25-32. doi:10.1016/j.mrgentox.2016.07.006.

[61] Y. Deng, E.J. Petersen, K.E. Challis, S.A. Rabb, R.D. Holbrook, J.F. Ranville, B.C. Nelson, B. Xing, Multiple Method Analysis of $\mathrm{TiO}_{2}$ Nanoparticle Uptake in Rice ( Oryza sativa L.) Plants, Environ. Sci. Technol. 51 (2017) 10615-10623. doi:10.1021/acs.est.7b01364.

[62] F. Piccinno, F. Gottschalk, S. Seeger, B. Nowack, Industrial production quantities and uses of ten engineered nanomaterials in Europe and the world, J. Nanoparticle Res. 14 (2012) 1109. doi:10.1007/s11051-012-1109-9.

[63] M. Kumari, A. Mukherjee, N. Chandrasekaran, Genotoxicity of silver nanoparticles in Allium cepa, Sci. Total Environ. 407 (2009) 5243-5246. doi:10.1016/j.scitotenv.2009.06.024.

[64] I.M. Prokhorova, B.S. Kibrik, A. V. Pavlov, D.S. Pesnya, Estimation of Mutagenic Effect and Modifications of Mitosis by Silver Nanoparticles, Bull. Exp. Biol. Med. 156 (2013) 255-259. doi:10.1007/s10517-013-2325-8.

[65] P. Cvjetko, A. Milošić, A.-M. Domijan, I. Vinković Vrček, S. Tolić, P. Peharec Štefanić, I. Letofsky-Papst, M. Tkalec, B. Balen, Toxicity of silver ions and differently coated silver nanoparticles in Allium cepa roots, Ecotoxicol. Environ. Saf. 137 (2017) 18-28. doi:10.1016/J.ECOENV.2016.11.009.

[66] P. Cvjetko, M. Zovko, P.P. Štefanić, R. Biba, M. Tkalec, A.-M. Domijan, I.V. Vrček, I. Letofsky-Papst, S. Šikić, B. Balen, Phytotoxic effects of silver nanoparticles in tobacco plants, Environ. Sci. Pollut. Res. (2017) 1-13. doi:10.1007/s11356-017-0928-8.

[67] K.K. Panda, V.M.M. Achary, R. Krishnaveni, B.K. Padhi, S.N. Sarangi, S.N. Sahu, B.B. Panda, In vitro biosynthesis and genotoxicity bioassay of silver nanoparticles using plants, Toxicol. Vitr. 25 (2011) 1097-1105. doi:10.1016/j.tiv.2011.03.008.

[68] M. Ghosh, A. Chakraborty, M. Bandyopadhyay, A. Mukherjee, Multi-walled carbon nanotubes (MWCNT): Induction of DNA damage in plant and mammalian cells, J. Hazard. Mater. 197 (2011) 327-336. doi:10.1016/j.jhazmat.2011.09.090.

[69] L.R. de Andrade, A. Sandin Brito, A.M.G. de Souza Melero, H. Zanin, H. José Ceragioli, V. Baranauskas, K. Silva Cunha, S. Pierre Irazusta, Absence of mutagenic and recombinagenic activity of multi-walled carbon nanotubes in the Drosophila wingspot test and Allium cepa test, Ecotoxicol. Environ. Saf. 99 (2014) 92-97. 
doi:10.1016/J.ECOENV.2013.10.013.

[70] S. Pakrashi, N. Jain, S. Dalai, J. Jayakumar, P.T. Chandrasekaran, A.M. Raichur, N. Chandrasekaran, A. Mukherjee, In Vivo Genotoxicity Assessment of Titanium Dioxide Nanoparticles by Allium cepa Root Tip Assay at High Exposure Concentrations, PLoS One. 9 (2014) e87789. doi:10.1371/journal.pone.0087789.

[71] M. Ruffini Castiglione, L. Giorgetti, C. Geri, R. Cremonini, The effects of nano-TiO2 on seed germination, development and mitosis of root tip cells of Vicia narbonensis L. and Zea mays L, J. Nanoparticle Res. 13 (2011) 2443-2449. doi:10.1007/s11051-0100135-8.

[72] M. Kumari, S.S. Khan, S. Pakrashi, A. Mukherjee, N. Chandrasekaran, Cytogenetic and genotoxic effects of zinc oxide nanoparticles on root cells of Allium cepa, J. Hazard. Mater. 190 (2011) 613-621. doi:10.1016/j.jhazmat.2011.03.095.

[73] T.C. Taranath, B.N. Patil, T.U. Santosh, B.S. Sharath, Cytotoxicity of zinc nanoparticles fabricated by Justicia adhatoda L. on root tips of Allium cepa L.-a model approach, Environ. Sci. Pollut. Res. 22 (2015) 8611-8617. doi:10.1007/s11356014-4043-9.

[74] A. Rajeshwari, S. Kavitha, S.A. Alex, D. Kumar, A. Mukherjee, N. Chandrasekaran, A. Mukherjee, Cytotoxicity of aluminum oxide nanoparticles on Allium cepa root tipeffects of oxidative stress generation and biouptake, Environ. Sci. Pollut. Res. 22 (2015) 11057-11066. doi:10.1007/s11356-015-4355-4.

[75] A. De, M. Chakrabarti, I. Ghosh, A. Mukherjee, Evaluation of genotoxicity and oxidative stress of aluminium oxide nanoparticles and its bulk form in Allium cepa, Nucl. 59 (2016) 219-225. doi:10.1007/s13237-016-0179-y.

[76] D. Nagaonkar, S. Shende, M. Rai, Biosynthesis of copper nanoparticles and its effect on actively dividing cells of mitosis in Allium cepa, Biotechnol. Prog. 31 (2015) 557565. doi:10.1002/btpr.2040.

[77] M. Faisal, Q. Saquib, A.A. Alatar, A.A. Al-Khedhairy, M. Ahmed, S.M. Ansari, H.A. Alwathnani, S. Dwivedi, J. Musarrat, S. Praveen, Cobalt oxide nanoparticles aggravate DNA damage and cell death in eggplant via mitochondrial swelling and NO signaling pathway, Biol. Res. 49 (2016) 20. doi:10.1186/s40659-016-0080-9.

[78] M. Faisal, Q. Saquib, A.A. Alatar, A.A. Al-Khedhairy, A.K. Hegazy, J. Musarrat, Phytotoxic hazards of NiO-nanoparticles in tomato: A study on mechanism of cell death, J. Hazard. Mater. 250-251 (2013) 318-332. doi:10.1016/j.jhazmat.2013.01.063.

[79] I. Manna, M. Bandyopadhyay, Engineered Nickel Oxide Nanoparticle Causes Substantial Physicochemical Perturbation in Plants, Front. Chem. 5 (2017) 92. doi:10.3389/fchem.2017.00092.

[80] A. Rajeshwari, B. Roy, N. Chandrasekaran, A. Mukherjee, Cytogenetic evaluation of gold nanorods using Allium cepa test, Plant Physiol. Biochem. 109 (2016) 209-219. doi:10.1016/J.PLAPHY.2016.10.003.

[81] A. Rajeshwari, S. Suresh, N. Chandrasekaran, A. Mukherjee, Toxicity evaluation of gold nanoparticles using an Allium cepa bioassay, RSC Adv. 6 (2016) 24000-24009. doi:10.1039/C6RA04712B.

[82] Q. Saquib, M. Faisal, A.A. Alatar, A.A. Al-Khedhairy, M. Ahmed, S.M. Ansari, H.A. Alwathnani, M.K. Okla, S. Dwivedi, J. Musarrat, S. Praveen, S.T. Khan, R. Wahab, M.A. Siddiqui, J. Ahmad, Genotoxicity of ferric oxide nanoparticles in Raphanus sativus: Deciphering the role of signaling factors, oxidative stress and cell death, J. Environ. Sci. 47 (2016) 49-62. doi:10.1016/J.JES.2015.12.037.

[83] İ.H. Ciğerci, R. Liman, E. Özgül, M. Konuk, Genotoxicity of indium tin oxide by Allium and Comet tests, Cytotechnology. 67 (2015) 157-163. doi:10.1007/s10616013-9673-0. 
[84] R. Grillo, Z. Clemente, J.L. de Oliveira, E.V.R. Campos, V.C. Chalupe, C.M. Jonsson, R. de Lima, G. Sanches, C.S. Nishisaka, A.H. Rosa, K. Oehlke, R. Greiner, L.F. Fraceto, Chitosan nanoparticles loaded the herbicide paraquat: The influence of the aquatic humic substances on the colloidal stability and toxicity, J. Hazard. Mater. 286 (2015) 562-572. doi:10.1016/J.JHAZMAT.2014.12.021.

[85] M.L. López-Moreno, G. de la Rosa, J.A. Hernández-Viezcas, H. Castillo-Michel, C.E. Botez, J.R. Peralta-Videa, J.L. Gardea-Torresdey, Evidence of the Differential Biotransformation and Genotoxicity of $\mathrm{ZnO}$ and $\mathrm{CeO}_{2}$ Nanoparticles on Soybean ( Glycine max ) Plants, Environ. Sci. Technol. 44 (2010) 7315-7320. doi:10.1021/es903891g.

[86] A. Mattiello, A. Filippi, F. Pošćić, R. Musetti, M.C. Salvatici, C. Giordano, M. Vischi, A. Bertolini, L. Marchiol, Evidence of Phytotoxicity and Genotoxicity in Hordeum vulgare L. Exposed to $\mathrm{CeO} 2$ and TiO2 Nanoparticles, Front. Plant Sci. 6 (2015) 1043. doi:10.3389/fpls.2015.01043.

[87] Abhishek Sadhu, Ilika Ghosh, Yuji Moriyasu, Anita Mukherjee, Maumita Bandyopadhyay, Role of cerium oxide nanoparticle-induced autophagy as a safeguard to exogenous $\mathrm{H} 2 \mathrm{O} 2$-mediated DNA damage in tobacco BY-2 cells, Mutagenesis. (2018). doi:10.1093/mutage/gey004.

[88] J.C. Stockert, M.E. Fernández-Gomez, G. Giménez-Martin, J.F. Lopez-Sáez, Behaviour of Nucleolar Organizers in Root-Tip Cells of Allium Cepa, Caryologia. 23 (1970) 37-43. doi:10.1080/00087114.1970.10796361. 


\section{Figures}

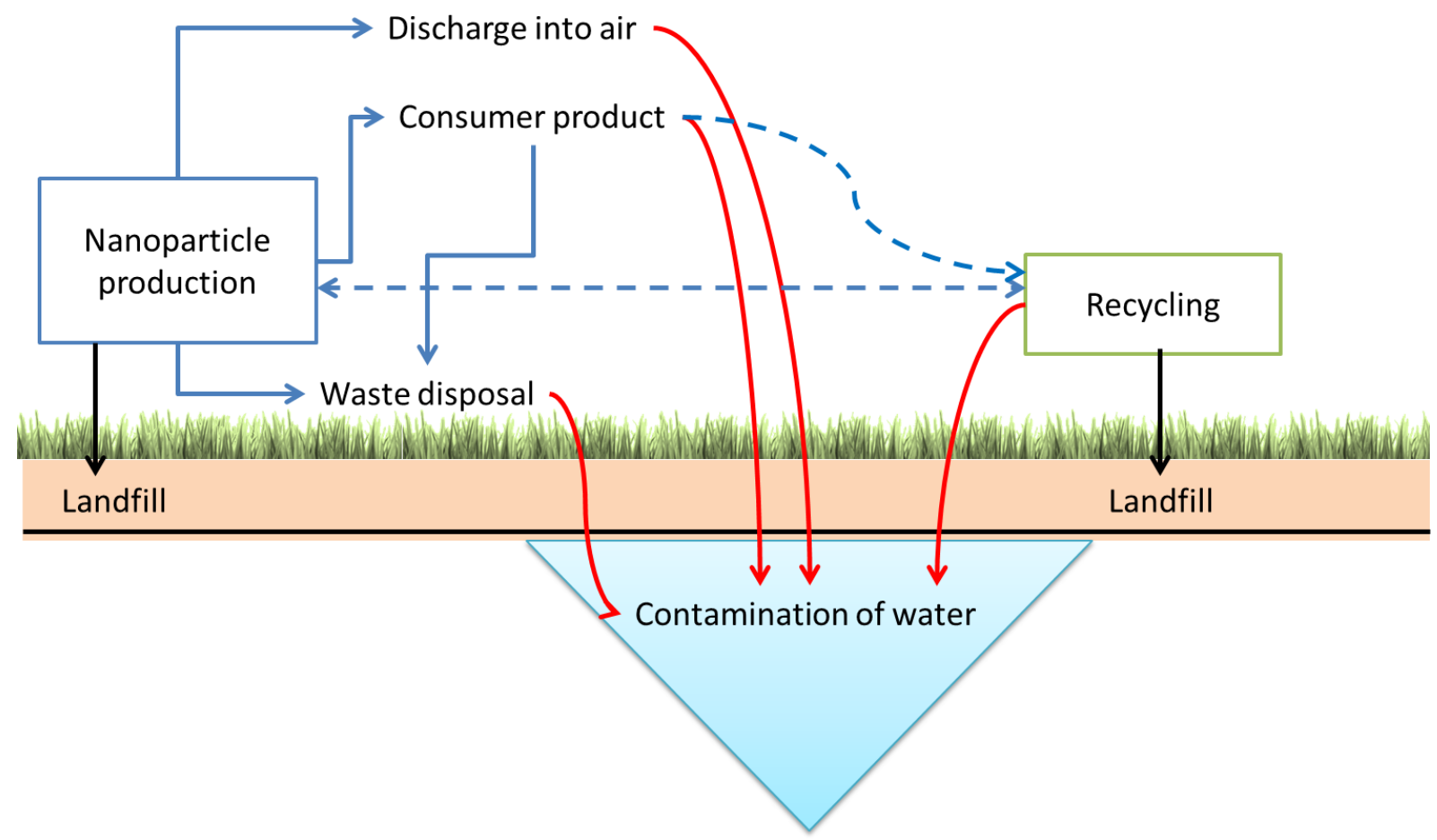

Figure 1: Schematic representation showing potential routes of nanoparticle (NP) release into the environment that could affect plants.

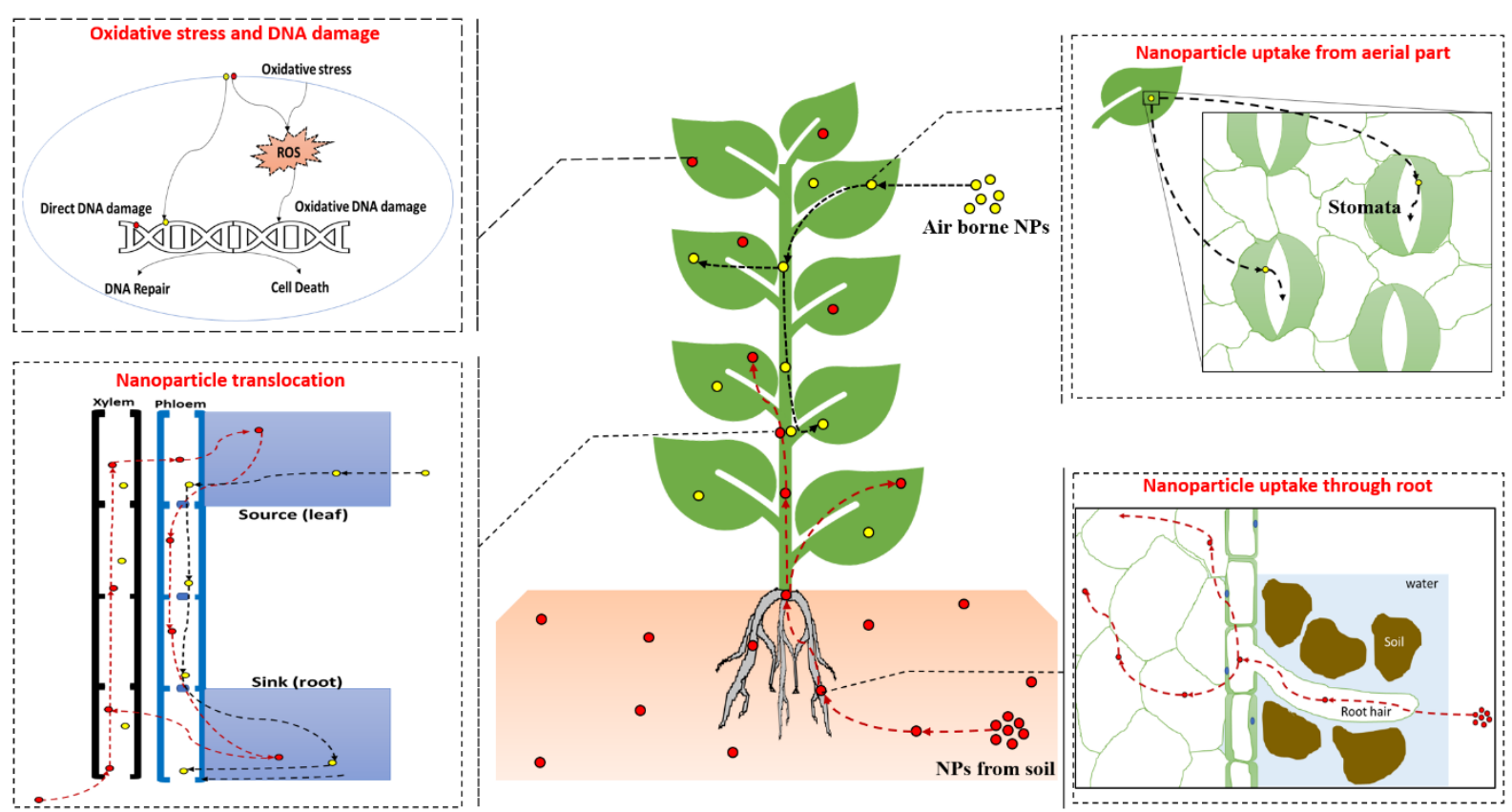

Figure 2: Schematic representation of possible routes of NP uptake in plant system through stomata or an opening in the root and subsequent translocation by xylem/phloem and biodistribution leading to localization, oxidative stress and genotoxicity in target cells. 


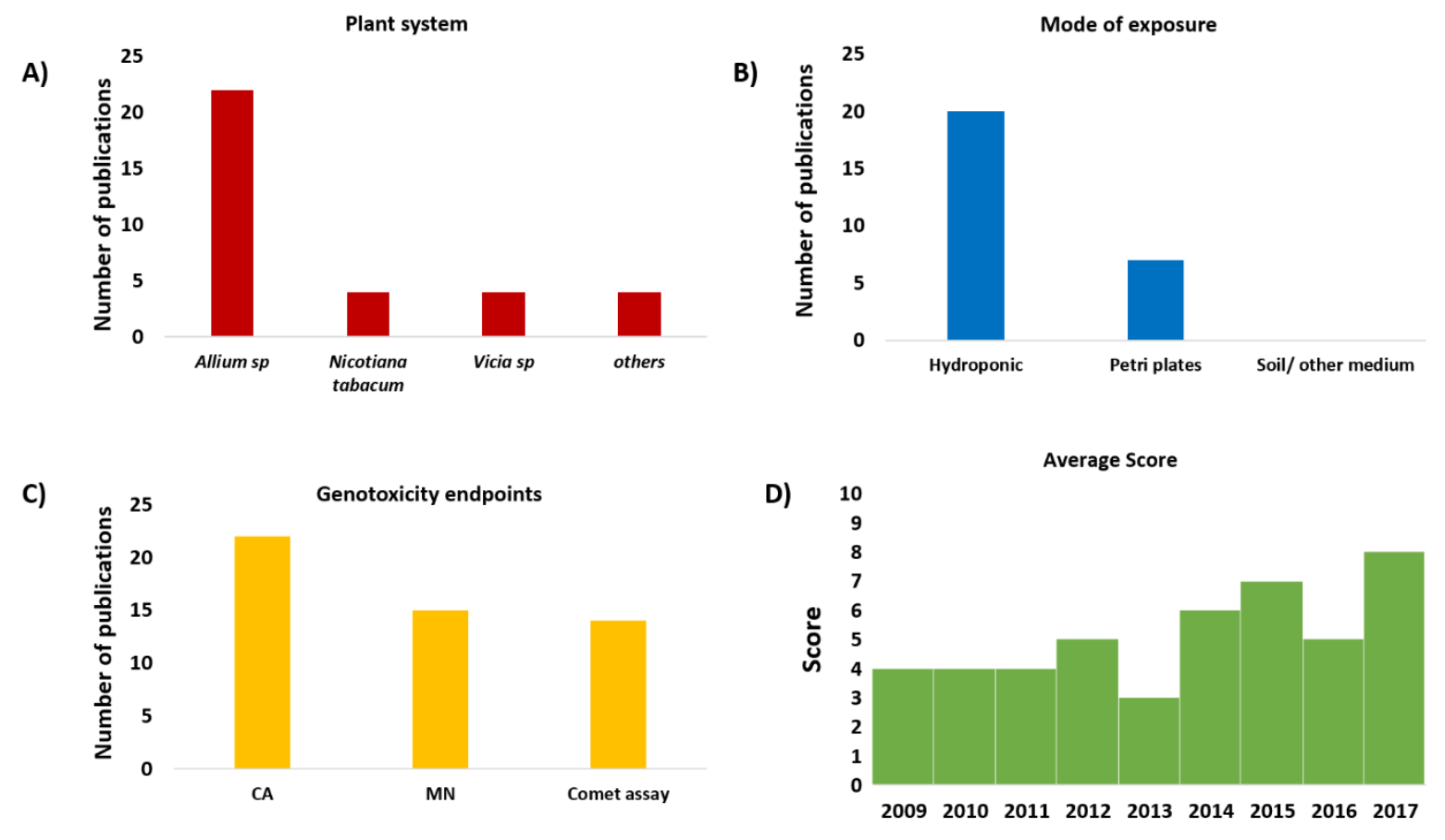

Figure 3: Summary of the reviewed studies showing number of publications A) using different plant systems, B) mode of NP exposure, and C) genotoxicity assays/endpoints studied. D) The average quality score for studies by year of publication. 